\title{
AS PRIMEIRAS EXPERIÊNCIAS DO MOVIMENTO DA MATEMÁTICA MODERNA NO COLÉGIO DE SÃO BENTO DO RIO DE JANEIRO
}

\author{
Bruno Alves Dassie ${ }^{1}$ \\ Universidade Federal Fluminense - UFF \\ Letícia Maria Ferreira da Costa $^{2}$ \\ Mestra em Ensino de Matemática - IM/UFRJ \\ João Bosco Pitombeira Fernandes de Carvalho ${ }^{3}$ \\ Universidade Federal do Mato Grosso do Sul-UFMS
}

\begin{abstract}
RESUMO
Apresentam-se resultados da pesquisa sobre as primeiras experiências do Movimento da Matemática Moderna no Colégio de São Bento do Rio de Janeiro. A partir de 1968, este colégio adotou como metodologia de ensino da disciplina Matemática a desenvolvida por Georges Papy. Notou-se que o colégio aderiu às propostas de Papy, com resultados positivos por mais de três décadas. A análise dessa experiência é feita sobretudo a partir de um considerável acervo escolar datado da década de 1970. Descrevem-se os conteúdos abordados pelo colégio, bem como a análise de como se deu o movimento no colégio - sua implantação, suas dificuldades e justificativas apresentadas pelo introdutor de Papy no colégio, Dom Ireneu Penna.

Palavras-chave: Movimento da Matemática Moderna; Colégio de São Bento; Georges Papy
\end{abstract}

\section{THE FIRST EXPERIENCES WITH THE NEW MATH MOVEMENT AT COLÉGIO DE SÃO BENTO IN RIO DE JANEIRO}

\begin{abstract}
The present article lays down research results on the first experiences on how the New Math Movement took place in a particular school, Colégio de São Bento, in Rio de Janeiro. For the mathematics curriculum, this particular school adopted, from 1968 on, the methodology proposed and developed by Georges Papy. The school used Papy`s schemes for more than thirty years with positive results. This experience is looked into mostly from an extensive list of copybooks and other school documents from a former student [1970`s]. An overview about the mathematical content covered by the school at that time is followed by an analysis of how the New Math Movement came to be at that school - its implementation, difficulties and justifications pointed out by the promoter of Papy`s method at the school, Dom Ireneu Penna.
\end{abstract}

Key-words: New Math Movement; Colégio de São Bento; Georges Papy; 


\section{Introdução}

Nas décadas de 1960 e 1970, o Brasil, aderiu à Reforma da Matemática Moderna, uma das principais reformas educacionais do século XX. Ainda hoje se sentem as decorrências destas reformas, que modificaram profundamente a matemática escolar. Grupos de estudos foram criados, novos livros didáticos foram produzidos na intenção de divulgar as novas ideias, novas experiências foram realizadas em muitas todas as escolas do país. Vivia-se a grande novidade da Matemática Moderna. Apesar de esta reforma, assim como outras reformas educacionais do século XX - Reforma Francisco Campos (1931) e Reforma Capanema (1942) - nem sempre ter contribuído positivamente para o aperfeiçoamento do ensino de matemática, ela ainda merece um olhar específico para suas diversas facetas. Como Chervel (1990) ressalta, é preciso dar importância a uma visão "mais global do problema, [das Reformas] associando-se às ordens do legislador ou das autoridades ministeriais ou hierárquicas, a realidade concreta do ensino nos estabelecimentos, e, algumas vezes, até mesmo às produções escritas dos alunos" (CHERVEL, 1990, p.1).

Neste contexto, este artigo faz um breve estudo de caso sobre uma experiência da Reforma da Matemática Moderna em um colégio de elite na cidade do Rio de Janeiro, o Colégio de São Bento (CSB). Como foi acolhida esta Reforma no CSB? Que características esta experiência apresenta? Quem a conduziu? Como a conduziu?

$\mathrm{O}$ presente trabalho traz à tona um caso singular do Movimento da Matemática Moderna (MMM). A experiência ocorrida no CSB possui um caráter individual. A partir de 1968, enquanto a maioria dos outros colégios da cidade embarcava nas ideias inovadoras do Movimento da Matemática Moderna na perspectiva americana, o Colégio de São Bento, por iniciativa própria, adotou "como método para a disciplina Matemática o desenvolvido pelo matemático [belga] Georges Papy” (SOARES, 2001, p. 95). Na época, os manuais didáticos de grande circulação eram os previstos e propostos por centros de referência tais como o Grupo de Estudos do Ensino da Matemática (GEEM), em São Paulo, muitos deles de autoria do professor Osvaldo Sangiorgi. O método do matemático belga Georges Papy vigorou por mais de duas décadas no CSB, que por sua vez demonstrou resultados positivos por meio desta sua inovação (SOARES, 2001).

Um resumo acerca das pesquisas sobre o MMM antecede uma breve apresentação do local onde se deu a experiência e da pessoa que a fez acontecer: o monge beneditino e professor Dom Ireneu Penna. Seguem-se a isto algumas considerações acerca das fontes utilizadas neste estudo de caso, a saber, um considerável acervo escolar encontrado com um ex-aluno. O acervo data da década de 1970 e constitui-se, sobretudo, de cadernos escolares dos anos do ginásio e do científico. Finalmente, a análise propriamente dita da experiência descreverá os conteúdos abordados pelo colégio e abordará como aí se deu o movimento - sua implantação e suas dificuldades e justificativas apresentadas pelo introdutor de Papy no CSB.

\section{As pesquisas sobre o Movimento da Matemática Moderna no Brasil}

Antes de aprofundarmos as considerações sobre nossa pesquisa, cabe analisar brevemente as características dos trabalhos já produzidos acerca do Movimento da Matemática Moderna no Brasil, a fim de melhor situar este trabalho.

Uma pesquisa realizada no banco de teses da CAPES $^{4}$ a partir da palavra chave Movimento da Matemática Moderna revelou dezesseis trabalhos que lidam direta ou indiretamente com este movimento. Destes, onze são dissertações de mestrado e cinco 
teses de doutorado. Cada uma dessas pesquisas focaliza um determinado aspecto do MMM em sua generalidade, no Brasil. São trabalhos sobre como a imprensa abordou o movimento, ou sobre alterações e orientações curriculares decorrentes do movimento, ou ainda sobre o ideário do Movimento entre professores de matemática. Existem ainda os trabalhos que analisam coleções de livros didáticos, de grande ou média circulação, que veicularam as ideias do Movimento até as escolas, ou ainda os que analisam a contribuição de determinado professor de grande importância durante o Movimento. Um exemplo desse último tipo é a dissertação de mestrado intitulada $O$ trabalho do professor Sylvio Nepomuceno - ajudando a reconstituir a história da educação matemática, ao tempo de influência do Movimento da Matemática Moderna, de Santander (2008). Há casos de análise de grupos de colégios, como a dissertação de Dobrowolsk (2011), cujo objetivo é investigar como a Matemática Moderna foi implantada, nos anos de 1960 e 1970, nas escolas de Pato Branco - PR. Um dos trabalhos de doutorado, Matemática e educação matemática: a dinâmica de suas relações ao tempo do movimento da matemática moderna no Brasil, apresenta o MMM somente como pano de fundo para a análise principal (DUARTE, 2007): investigar a dinâmica das relações entre Matemática e Educação Matemática. Para tanto, a autora estuda a época do Movimento, mas não discute o Movimento propriamente dito, suas intenções, dificuldades, aceitação, contribuição.

Entre as fontes utilizadas pelas dissertações e teses acima mencionadas encontramos livros didáticos - considerados individualmente ou em coleções - da época em que o movimento vigorou no Brasil (BRITO, 2008; COLAÇO, 2010), além de documentos oficiais tais como leis, diretrizes ou currículos (FRANÇA, 2007), arquivos escolares, arquivos pessoais ou institucionais (DOBROWOLSK, 2011; DUARTE, 2007) e artigos de jornais ou revistas. Algumas pesquisas também se baseiam em depoimentos orais de indivíduos que tiveram participação ativa durante o Movimento, professores, autores de livros ou até mesmo ex-alunos (FIETTA, 2010; SOARES, 2001, DOBROWOLSK, 2011).

As pesquisas citadas acima, notadamente a de Soares (2001), indicam que no Brasil predominou uma vertente específica do MMM. Nosso país, assim como quase toda a América Latina, foi fortemente influenciado pelas tendências e ideias norte americanas (MATOS; VALENTE, 2010). A ideologia proposta pelos Estados Unidos, os conteúdos que eles preconizavam, a metodologia, assim como outros aspectos educacionais da Reforma da Matemática Moderna americana foram absorvidos e adaptados no Brasil. Tal corrente fez com que o MMM adquirisse certa homogeneidade nos principais centros de ensino do país. Em diferentes estados seguiam-se, grosso modo, as mesmas normas. Reforçam esta conclusão as pesquisas de Soares (2001) e as produções de Matos e Valente (2007, 2010), além do simples fato de que, ao ser questionado sobre o que pensa ou lembra acerca da Matemática Moderna, um cidadão comum que tenha sido aluno entre as décadas de 1960 e 1970 responderá "Ah! Aquele negócio de teoria dos conjuntos". Tais fatos não refletem a existência de múltiplas facetas, concomitantes e com importâncias equivalentes, de um mesmo e único movimento.

Uma característica da maioria das produções acadêmicas que dissertam sobre o referido MMM é a predominância de estudos advindos de um único Estado. Percebe-se que os estudos focalizam, sobretudo, o Estado de São Paulo. Atualmente, a maioria das pesquisas sobre o MMM é realizada a partir de projetos do professor Dr. Wagner Rodrigues Valente (UNIFESP), responsável pelo Grupo de Pesquisa de História da Educação Matemática (GHEMAT) no Brasil ${ }^{5}$. Tais pesquisas são fomentadas, em especial, pelo conjunto de arquivos pessoais que o referido grupo possui, principalmente o dos professores Scipione Di Pierro Netto e Osvaldo Sangiorgi. Em relação aos trabalhos 
que fazem referência ao Estado do Rio de Janeiro, após a pesquisa de Soares (2001) localizamos apenas a pesquisa de Villela (2009), que apresenta uma análise de duas coleções de livros didáticos, uma delas associada ao Grupo de Ensino de Matemática Atualizado (GRUEMA) que contava com algumas autoras do Rio de Janeiro. Diversos fatores explicam esta concentração de pesquisas no Estado de São Paulo, um deles a disponibilidade e localização das fontes. Dessa maneira, observa-se pelas pesquisas que a influência europeia no país ainda não foi tão investigada, em suas especificidades, quanto a americana, e que as experiências desse movimento no Estado do Rio de Janeiro ainda são campo fértil para pesquisas em perspectiva histórica.

\section{O Colégio de São Bento do Rio de Janeiro}

Fundado em 1858, o Ginásio de São Bento - mais tarde Colégio de São Bento - é uma instituição de ensino associada ao Mosteiro de São Bento da cidade do Rio de Janeiro, pertencente à ordem beneditina. Ao ser criado, os únicos responsáveis pelo ensino dos alunos eram os monges do referido mosteiro, que acolhiam os jovens, somente do sexo masculino, e lhes ensinavam nas próprias dependências do mosteiro. Se de início o Colégio oferecia atendimento gratuito - inclusive com a opção de uma escola noturna que funcionou de 1908 a 1938 - as circunstâncias, ao passar dos anos, acabaram obrigando os monges do Mosteiro a cobrar, de início, "módicos 30 mil reis", o que pagaria as taxas de secretaria e o salário dos professores. Com o passar dos anos os monges abriram as portas a funcionários leigos, apesar de, até os dias atuais, as portas permanecerem fechadas a alunos do sexo feminino.

O CSB funciona atualmente em regime semi-interno, e assim o era na década de 1970. O currículo do curso ginasial naquela época contava com as disciplinas Português, Latim, Francês, Inglês, Matemática, Ciências, História Geral e do Brasil, Geografia Geral e do Brasil, Estudos Sociais, Desenho e OSPB ${ }^{6}$. Nem todas estas disciplinas constavam nos programas de todas as séries do curso ginasial. Algumas eram dadas num ano e noutro não.

Como a demanda de matrículas cresceu ao longo dos anos, a direção do colégio viu-se obrigada a limitar as vagas e assim impôs o regime de seleção por meio de provas de matemática e português. Só há ingresso de alunos na primeira série de cada ciclo. Este regime de seleção já era utilizado na década de 1970.

O CSB sempre foi considerado um colégio de alto nível de ensino, sendo os diretores, e mais tarde os reitores, pessoas que se destacaram no cenário educacional do Brasil em diversos momentos, a começar pelo próprio fundador do Ginásio de São Bento, Frei Luís da Conceição Saraiva, que foi vice-diretor do Colégio Pedro II (FRAZÃO, NOUGUÉ, 2008). Mais tarde, já no século XX, o colégio usufruiu das competências de Dom Lourenço de Almeida Prado, reitor do colégio de 1955 a 2001. Concomitantemente ao cargo de reitor do CSB, Dom Lourenço exerceu diversos cargos na área educacional: presidente da Associação de Educadores Católicos da Guanabara; membro do Conselho Estadual de Educação; membro fundador da Academia Brasileira de Educação e membro do Conselho Federal de Educação (ibid, p. 110). Como indicam Frazão e Nougué, Dom Lourenço foi "grande educador, reconhecido, admirado e respeitado por sua cultura e capacidade [...] [e] colocou o Colégio nos primeiros lugares de todas as pesquisas nos últimos anos" (ibid, p. 110).

Atualmente o CSB é considerado um colégio de elite, apesar de este não ser o perfil que sempre vigorou no colégio. Na década de 1970, segundo depoimentos dos ex-alunos da época, ingressavam no colégio meninos de todos os níveis sociais. Bolsas de estudo 
eram concedidas aos menos afortunados e as diferentes turmas gozavam de uma mistura social saudável.

\section{Dom Ireneu Penna}

Weimar Penna, como foi batizado o futuro Dom Ireneu, possuía um espírito científico e professoral. Graduou-se em engenharia civil pela Escola Politécnica da Universidade do Brasil (1937) ao mesmo tempo em que concluía o Curso de professor secundário de matemática na Escola de Ciências da Universidade do Distrito Federal.

Antes de ingressar no Mosteiro de São Bento em 1941, Weimar Penna exerceu atividades e ocupou cargos de destaque no plano educacional. Em 1938 foi nomeado para o cargo de oficial do gabinete do Secretário Geral de Educação e Cultura do Distrito Federal, Dr. Paulo de Assis Ribeiro; neste mesmo ano, tornou-se Professor Adjunto da Seção de Didática da Universidade do Distrito Federal. Após retornar da Universidade de Sorbonne onde obteve os certificados de estudos superiores em Morale et Sociologie e em Psychologie, foi professor de matemática na Escola Nacional de Medicina. Na Faculdade de Educação, lecionou Filosofia da Educação. Mais uma vez vê-se um (futuro) monge do Mosteiro de São Bento com fortes ligações com a Educação.

Como monge do Mosteiro de São Bento, instituição que não desprezou sua vocação para o magistério, "foi Dom Ireneu o grande professor de matemática do CSB" (MOSTEIRO DE SÃO BENTO, 2008, p. 59), exercendo este cargo de 1947 a 1976. Também foi professor de desenho, religião e filosofia além de ser um monge alpinista que levava em excursão seus alunos para as diversas trilhas e montanhas da cidade do Rio de Janeiro.

Mesmo dentro do Mosteiro, Dom Ireneu continuou a exercer atividades externas. Em 1957 começou a lecionar Filosofia e Teoria do Conhecimento no Instituto de Filosofia e Ciências Sociais da UFRJ. Devido aos avanços esquerdistas que tumultuaram o ensino do Brasil nesta segunda metade do século XX, ele pede sua demissão ao cargo em 1968 e denuncia em carta aberta "o terror cultural montado [por um grupo] na escola com o objetivo de afastar os professores não marxistas" (DOM IRENEU, 1968). Com o afastamento de certos professores, este grupo ficaria mais à vontade quanto à sistemática pedagógica. "Visavam criar uma situação insustentável para alguns dos professores mais capazes, possuidores de um cabedal humanístico que os credencia a desenvolverem pesquisas filosóficas de alto nível" (ibid). Dom Ireneu era um destes professores e seu afastamento teria sido considerado, segundo o jornal O Globo (05 de setembro de 1968, p. 3) um degrau conquistado para este grupo, não fosse a repercussão das denúncias feitas pelo monge-professor.

Percebe-se daí o caráter forte deste monge. O ex-aluno e amigo, Francisco Nóbrega, testemunha que "esse gosto por uma boa polêmica era um traço importante da personalidade de D. Ireneu". Este temperamento forte será ainda responsável pelo enfrentamento de algumas barreiras e discussões no momento em que ele decide introduzir o Método Papy para a disciplina Matemática no Colégio de São Bento, e pelo combate contra os educadores que achavam que não existia raciocínio lógico antes de certa idade. $\mathrm{O}$ ex-aluno Francisco Nóbrega, que também foi professor do CSB, comenta que esta questão do raciocínio lógico constituía uma "cruzada" para Dom Ireneu.

Suas fortes convicções educacionais, pedagógicas e científicas acabaram afastandoo do Colégio de São Bento. Ele decidiu retirar-se (1976) do lugar onde tanto trabalhara justamente por defender que a Matemática Moderna [de Papy] fosse estendida para o ensino médio; o reitor, Dom Lourenço de Almeida Prado, não concordava com isso. 
Dom Ireneu faleceu em 2008. Sobre ele, o escritor brasileiro Gustavo Corção escreve:

\begin{abstract}
Dom Ireneu [...] foi sempre o nosso mestre, o porto seguro da inteligência espaçosa, clara e firme que sempre procuramos nos momentos em que até as constelações pareciam delirar. [...] Obscuro, modesto, ignorado pela grande publicidade [...], Dom Ireneu desfruta, entretanto, um sólido prestígio dentro do grupo dos ex-alunos que descobriram, como nós, a largueza e a beleza de sua inteligência. [...] Nas horas de recreio, Dom Ireneu pratica a fotografia e o alpinismo, por onde se vê que é reincidente, sob todas as formas, o seu gosto de subir e seu gosto de gravar a verdade das coisas (CORÇÃO, 1972 apud MOSTEIRO DE SÃO BENTO, 2008, p.60).
\end{abstract}

Este apreço e busca pela verdade das coisas será ainda notado no momento em que Dom Ireneu justifica sua opção pelo Método Papy, como adiante se verá.

\title{
5. Das fontes
}

Neste estudo de caso recorre-se a uma pluralidade de tipos de fontes históricas.

A principal fonte é o conjunto de documentos do acervo escolar de Tiago Ferreira da Costa, ex-aluno do CSB e em particular ex-aluno de Dom Ireneu. O acervo data do início da década de 1970 e consiste quase que na totalidade do material escolar de matemática das quatro séries do ginásio e das três do curso científico (que corresponde ao atual ensino médio) do referido ex-aluno. $\mathrm{O}$ material foi cedido temporariamente para que se fizessem estudos e pesquisas sobre as primeiras experiências do Movimento da Matemática Moderna neste colégio ${ }^{7}$.

Essencialmente, os documentos do acervo são cadernos escolares, listas de exercícios com algumas de suas respectivas resoluções, provas/testes e fragmentos de apostilas de conteúdo. Totalizando seis unidades, os cadernos varrem os anos desde 1971, quando o ex-aluno cursava o $2^{\circ}$ ano ginasial (atual $7^{\circ}$ ano do Fundamental), até 1976, ano em que ele deixou o Colégio, ao terminar o $3^{\circ}$ ano científico (atual $3^{\circ}$ ano do Ensino Médio). Apenas um dos seis cadernos não está datado, porém uma análise de conteúdo, corroborada pelo testemunho do próprio ex-aluno, permite inferir o ano e série escolar correspondente. Em alguns dos cadernos podem-se ler nomes de professores tais como o de Dom Ireneu Penna, Miguel Jorge, Morgado e Maria Amélia.

As quase trinta listas de exercício perfazem um total de mais de 600 tarefas, as quais abordam conteúdos de todas as séries iniciais, inclusive da $1^{\text {a }}$ série ginasial (da qual não possuímos o caderno), e dos anos do curso científico. Dentre as listas, algumas vêm acompanhadas das resoluções do próprio ex-aluno. Cabe ressaltar que estas listas estão sem data, mas, como veremos mais adiante, isto não foi impedimento para se identificar as séries às quais cada uma delas faz referência.

As provas e testes são relativos apenas ao $2^{\circ}$ e $4^{\circ}$ anos do ginásio e aos dois primeiros anos do científico. Em todos estes documentos constam o nome do aluno, a série, a data e o nome do professor. Com exceção de duas num total de vinte e três provas, todas elas acompanham a respectiva resolução do ex-aluno, a correção do professor e a nota atingida.

Além disso, entre os cadernos e listas de exercício foram encontrados seis diferentes documentos, os quais foram identificados como parte de um capítulo dos 
Apontamentos de Matemática, as apostilas escritas e utilizadas por Dom Ireneu em suas aulas, no ginásio, seguindo os conteúdos e métodos propostos por Papy. Chamamos estes documentos de fragmentos de apostilas. Cabe ressaltar que alguns destes fragmentos são cópias dos manuscritos de Dom Ireneu.

Considera-se que todo este acervo, especialmente os cadernos, é de grande relevância para a historiografia da Educação Matemática, pois o material mostra de maneira ímpar o que foi vivido em sala de aula. Acreditamos serem tais cadernos uma fonte de grande valia, como afirma Antonio Viñao (2008):

Se um dos problemas mais característicos da implantação e difusão das reformas e inovações é a defasagem ou distância existente entre as propostas teóricas, a legalidade e as práticas docentes e discentes, os cadernos escolares constituem uma fonte valiosa na hora de conhecer e analisar de um modo bastante confiável tanto os processos de implantação e difusão mencionados como os de hibridação (VIÑAO, 2008, p. 17).

Neste caso, a incorporação das propostas para o ensino da Matemática implantadas no Colégio de São Bento e influenciadas diretamente pelo Movimento da Matemática Moderna.

Cabe ainda ressaltar, como destaca Silvina Gvirtz (1999), que os cadernos escolares, usados constantemente pelos alunos

[...] tanto para registrar mensagens como para desenvolver atividades, reúnem duas condições que o tornam objeto de interesse. A primeira, sua capacidade de conservar o registrado, caráter que os distinguem de outros processos de escrituração. [...] A segunda é o fato de ser o caderno um espaço de interação entre professores e alunos, uma arena onde cotidianamente se enfrentam os autores do processo de ensinoaprendizagem e onde, dessa forma, é possível vislumbrar os efeitos da atividade tarefa escolar (GVIRTZ, 1999, p.12, tradução nossa).

E ainda,

o caderno não pode ser analisado somente [da] perspectiva [de um] simples reflexo das atividades escolares, ou seja, como memória neutra destas. Ainda que só o considerem de maneira anatômica, não se pode dizer que escrever em folhas soltas ou em lousas produza os mesmos resultados [...] que quando se trabalha com um caderno (GVIRTZ, 1999, p. 14, tradução nossa).

Assim, para nos aproximarmos de maneira não ingênua dos efeitos dos cadernos, torna-se necessário abordá-los considerando-os como produto de efeitos, como operador ou [...] como dispositivo escolar. (GVIRTZ, 1999, p. 14)

Portanto, para enriquecimento da pesquisa e como fator de entendimento das fontes escolares citadas e de seu contexto, fazem-se necessários outros tipos de fontes, sobretudo aquelas que têm a possibilidade de revelar informações específicas acerca da introdução do Método Papy no CSB. Dessa forma, foram coletados artigos de jornal da época que tratassem do tema Matemática Moderna no Rio de Janeiro, na década de 1970, para analisar se houve ou não e qual foi a repercussão da iniciativa do CSB no então Estado da Guanabara, hoje o Município do Rio de Janeiro. 
Além dos recortes de jornal encontrados, o arquivo pessoal de Dom Ireneu, que se encontra no acervo do Mosteiro de São Bento do Rio de Janeiro, demonstrou conter um conjunto considerável de fontes. Aí se encontra, além de outros documentos e materiais que ele próprio usava em suas aulas de matemática, uma circular que ele escreveu aos pais e responsáveis na época em que revolucionou o colégio com a adoção dos manuais de Papy.

Para auxiliar o processo de interpretação e reconstituição de como se deu a iniciativa de Dom Ireneu, foram, além disso, coletados testemunhos orais de dois exprofessores do CSB que atuaram diretamente junto a Dom Ireneu no processo de implementação do Método Papy: os professores José Paulo Quinhões Carneiro e Sandra Carelli. Sérgio Lúcio Miranda e Francisco Nóbrega, dois ex-alunos do CSB do período em questão, também contribuíram com depoimentos. Estes depoimentos orais acrescentam-se aos cadernos escolares e completam assim um conjunto de fontes, pois como Viñão (2008) salienta,

Se [...] os cadernos escolares devem ser situados como fonte histórica no contexto das práticas e pautas escolares, sociais e culturais de sua época, seu uso há de completar-se e combinar-se com outras fontes históricas (VIÑAO, 2008, p. 27).

No contexto da introdução do Método Papy no CSB, as listas de exercícios e provas, os depoimentos orais, os recortes de jornais e os documentos do arquivo pessoal de Dom Ireneu completam os cadernos, complementando-se e completando-se.

Desta maneira, todas essas as fontes são de grande importância no momento de recompor e avaliar o conjunto das experiências vividas dentro do Colégio de São Bento principalmente por alunos, pais e professores. Esta prática única do Movimento da Matemática Moderna deve ser entendida como um fenômeno social e cultural (GAVROGLU, 2007), ainda que localmente, a saber, no âmbito restrito de um colégio dirigido por monges beneditinos no estado do Rio de Janeiro, no qual só rapazes eram admitidos.

\section{O Método Papy no Colégio de São Bento: as primeiras experiências}

\subsection{Sequência dos conteúdos de Matemática nos anos de Ginásio e de Científico do Colégio de São Bento na década de 1970}

A análise da sequência de conteúdos foi realizada, principalmente, a partir dos cadernos de aula, ratificada e complementada pelas listas de exercícios, provas, e (fragmentos de) apostilas ${ }^{8}$. A seguir estão relatados mais detalhadamente os conteúdos de matemática e a sequência em que eram ministrados ano a ano, bem como uma relação entre as escolhas de Dom Ireneu e os livros de Papy.

a) Curso Ginasial:

Apesar da falta do caderno do $1^{\mathrm{o}}$ ano ginasial, suprida em grande parte pelos Apontamentos de Matemática I, foi possível um delineamento da trajetória de conteúdos escolhida por Dom Ireneu (no ginásio) e pelos outros professores já mencionados (no científico) para estes sete anos de formação no Colégio de São Bento.

Iniciando a $1^{\text {a }}$ série ginasial, aos 11 ou 12 anos, o aluno do CSB era introduzido à Matemática Moderna estudando as primeiras noções de teoria dos conjuntos. A álgebra dos conjuntos era considerada matéria de base para a sequência de conteúdos proposta por 
Papy. Ele indica que "a álgebra dos conjuntos introduz um cálculo cujas regras são as mesmas que as da aritmética elementar, o que permite, de maneira particular, colocar em relevo as características próprias do cálculo algébrico usual" (PAPY, 1968, v.1, p.VI), que será trabalhado com mais ênfase e detalhes nos anos seguintes. Nota-se que, apesar da expressão "primeiras noções de conjuntos", o que se aprendia não era tão primário assim. Por exemplo, já na $1^{a}$ série ginasial se introduzia a ideia de Conjunto das partes de um conjunto assim como de Partição de um conjunto. Dom Ireneu ressalta no prefácio dos Apontamentos de Matemática I que o grau de abstração adquirido pelos alunos ao final do ano era altíssimo. Este grau de abstração continua a ser desenvolvido por meio da noção de relação, após uma breve introdução à geometria afim do plano (conjuntos de pontos, retas, axiomas do plano, posições relativas das retas) que, por sua vez, faz uso das noções de conjuntos adquiridas anteriormente. $\mathrm{O}$ estudo das relações ainda se estende ao longo de cinco capítulos dos Apontamentos de Matemática I, com complexidades gradativamente maiores, culminando na abordagem das funções, consideradas um tipo especial de relação. Antes disso, foram estudadas ideias de relação composta, gráfico de uma relação e propriedades de uma relação. Constam também estudos sobre relações de Ordem. O capítulo Cardinais finaliza a matéria da $1^{\text {a }}$ série ginasial. Neste, são fornecidos meios intuitivos para um estudo primário dos cardinais, assim como uma caracterização dos conjuntos finitos e infinitos segundo a visão de Dedekind. Teoremas como o da Injeçãao ${ }^{9}$ e do Sanduiche ${ }^{10}$ são também mencionados.

A partir do $2^{\circ}$ ano ginasial, a análise de conteúdos passa a contar com as fontes primárias, os cadernos. Precedido de revisões dos principais conceitos adquiridos no ano anterior, a $2^{\mathrm{a}}$ série dedica seus primeiros momentos ao estudo da adição e multiplicação (e divisibilidade) dos cardinais. Por meio dos cadernos, é possível notar que estas teorias são constantemente apresentadas em analogia direta com a teoria dos conjuntos e das relações, estabelecendo vínculos entre os conhecimentos anteriores sobre a aritmética elementar e os estudos sobre conjuntos. A numeração de posição, estudada sob o contraste entre a numeração binária e a decimal, é o tema seguinte, antecedendo o estudo do anel dos inteiros racionais, quando se aprofunda mais o estudo da aritmética. Nesta etapa já são resolvidas equações em $\mathbb{Z}_{,}+$.

Dando continuidade à matéria, explicitamente à construção da geometria no plano, estudam-se estruturas vetoriais: eqüipolências, translações, projeções paralelas. Combinando intimamente a álgebra e a geometria, termina-se o $1^{\circ}$ ano ginasial estudando simetrias centrais e as características de grupo que estas apresentam. Ressalta-se que é um desejo, ou estratégia pedagógica de Papy que a definição formal de grupo, ou até mesmo a palavra "grupo" ainda não apareça neste momento, apesar de as características de grupo já virem sendo apresentadas sob diversas formas nos tópicos anteriores: "de maneira implícita, [...], quando se abordou a álgebra dos conjuntos e a diferença simétrica, e de maneira mais explícita ao se abordar o conjunto das permutações, o conjunto aditivo dos inteiros racionais, o conjunto das translações e das simetrias centrais" (PAPY, 1968, v. 1, p. VIII).

Os Apontamentos de Matemática II, relativo ao $2^{\circ}$ ano ginasial, dedica o último capítulo a grupos, quando expõe sua definição formal. Apresentam-se os grupos cíclicos e estudam-se equações em um grupo qualquer. No entanto, no caderno do $2^{\circ}$ ginasial do acervo escolar, o tema grupos não figura tão explicitamente assim. As últimas anotações são sobre simetrias paralelas. O tema grupos consta do início do caderno do $3^{\circ}$ ginasial, juntamente com o tema ordem. Na seqüência são abordados temas como grupos ordenados, inequações, isomorfismos, ordem natural de Z, função crescente e decrescente, graduação binária $^{11}$, axioma de Arquimedes. Todos estes conteúdos seguem de maneira muito fiel os 
constantes nos cinco primeiros capítulos de Mathématique Moderne II. Ao iniciar seu livro com estes conteúdos, Papy "pretende essencialmente construir o campo dos números reais e o plano vetorial euclidiano" (PAPY, 1968, v. 2, p.VI), o que mais adiante Dom Ireneu também fará. Em seguida são estudados os números reais e a estrutura $R_{y}+$, seguidos imediatamente por um estudo sobre erros e aproximações. Logo após, as homotetias são amplamente exploradas, precedendo o enunciado do teorema de Tales. Finalmente, antes de abordar o campo ordenado dos números reais e suas regras, faz-se o estudo da multiplicação dos reais e da multiplicação por escalar, assuntos dentre os quais estão incluídos equações em $R_{0}$, frações (inverso do produto), comutatividade e linearidade das homotetias, razão de vetores paralelos e projeções paralelas. Os Apontamentos de Matemática III ainda possui um último capítulo, o espaço vetorial $\left(\mathbb{R}_{,} \mathrm{D}_{0_{0}}+\right)$, que não consta do caderno do $3^{\circ}$ ano ginasial.

$\mathrm{Na}$ última série ginasial, com 14 anos aproximadamente, o aluno do Colégio de São Bento continuava seus estudos de Matemática Moderna explorando o cálculo em $(\mathrm{R},+$, ,., $\leq$ ), reunindo e classificando os resultados obtidos anteriormente. Neste quadro são desenvolvidos temas como potências e ordem, sequências lineares, quadrado de uma soma e diferença de quadrados [de números reais]. No cálculo numérico estudam-se a multiplicação de binários ${ }^{12}$ e decimais limitados e ilimitados. Segue-se a isso uma seção sobre os reais racionais e irracionais, que contempla, para citar alguns tópicos, divisão arquimediana, densidade de $\mathbb{Q}$ e cardinalidade do conjunto dos números irracionais. Em seguida, com a introdução do espaço vetorial $\left(R, \pi_{\mathrm{o}},+\right)$ e seu desenvolvimento subseqüente, passa-se ao tópico equações das retas do plano. Seguem-se, nesta ordem, semi-planos, inequações e sistemas de equações lineares, cada um desses assuntos com seu respectivo desenvolvimento, aplicações e conclusões. Soma-se a isso o estudo de raízes quadradas, racionalização de denominadores e equações do $2^{\circ}$ grau. As últimas anotações do caderno da $4^{\text {a }}$ série ginasial referem-se a gráficos cartesianos de funções, simetrias centrais e simetrias paralelas. Estes dois últimos tópicos pertencem a uma parte dos Apontamentos de Matemática IV intitulada Geometria Euclidiana Plana. Nessa, constam ainda os seguintes capítulos: simetrias ortogonais, isometrias, deslocamentos, rotações, grupo dos deslocamentos, reviramentos, distância, círculos, e por último, produto escalar. Nenhum destes tópicos está registrado no caderno do $4^{\circ}$ ano ginasial, mas os encontramos todos nos registros do caderno do $1^{\mathrm{o}}$ ano científico. Uma hipótese para esta diferença é que, ao longo dos anos, Dom Ireneu percebeu que poderia, ou conseguia introduzir estes assuntos ainda no ginásio, como Papy propõe (PAPY, 1968, v. 3).

b) Curso Científico:

Como já mencionado acima, os tópicos simetrias ortogonais, isometrias, deslocamentos, rotações, grupo dos deslocamentos, reviramentos, distância, círculos e produto escalar são os constantes no caderno do $1^{\circ}$ ano científico, apesar de esta ordem não ter sido mantida. A estes temas acrescentam-se: desigualdades (triangular, de CauchySchwartz e de Minkowski), equações de retas perpendiculares, distância (orientada) de um ponto a uma reta, equações normais de retas e equação da bissetriz em função das retas determinadas pelos lados do ângulo.

No $2^{\circ}$ ano científico, a trigonometria é estudada em todos seus detalhes ocupando grande parte do currículo. Segue-se a isto a álgebra linear, igualmente aprofundada. Ainda são contemplados, sem superficialidade, polinômios (raízes, sinal, gráficos), progressões aritméticas e geométricas (PA e PG), funções exponencial e logarítmica, análise combinatória, probabilidades e números complexos. 
O último caderno examinado, o do $3^{\circ}$ ano científico, está dividido em duas partes: análise e álgebra linear. Na primeira parte encontram-se estudos mais amplos e mais teóricos sobre a teoria dos conjuntos, conjuntos numéricos, (tipos de) funções e matrizes (um operador de transformações). A segunda parte contempla um estudo mais formal sobre vetores, incluindo interpretações geométricas de operações entre vetores, triedros e tetraedros, dependência e independência linear. Percebe-se que também foi realizado um estudo considerável de aplicações da álgebra linear à geometria analítica. Paralelismo e perpendicularismo em $R^{2}$ e em $R^{3}$, círculo, esfera, parábola, elipse e hipérbole são alguns dos tópicos encontrados ao final do caderno.

Da análise dos conteúdos registrados nos cadernos e nas apostilas de conteúdo, infere-se que, de maneira geral, Dom Ireneu seguiu o proposto por Papy em seus três primeiros volumes de Mathématique Moderne, tanto para ministrar suas aulas quanto para elaborar seus Apontamentos de Matemática. Esta correspondência de conteúdos existe para todos os anos ginasiais e para o $1^{\circ}$ ano científico. Os conteúdos abordados no $2^{\circ}$ e no $3^{\circ}$ ano científico no CSB não figuram naqueles três primeiros volumes de Papy nem no restante da coleção Mathématique Moderne, que conta com mais dois volumes editados (volumes 5 e 6) e um nunca editado (volume 4).

As tabelas abaixo apresentam a correspondência para as séries do ginásio, segmento escolar no qual houve maior concordância em relação às propostas de Papy.

Tabela com correspondência entre os textos didáticos

\begin{tabular}{|c|c|c|c|}
\hline & Apostilas de Dom Ireneu & Manuais de Papy & \\
\hline \multirow{14}{*}{ 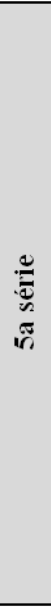 } & Cap I - Conjuntos - Primeiras noções & MM1: Cap 1 - Ensembles & \multirow{14}{*}{ MM1 } \\
\hline & Cap II - Conjuntos - Inclusão & MM1: Cap 2 - Parties & \\
\hline & Cap III - Álgebra dos Conjuntos & $\begin{array}{l}\text { MM1: Cap } 3 \text { - Intersection - Réunion-Différence } \\
\text { Cap } 4 \text { - Algèbre des Ensembles }\end{array}$ & \\
\hline & Cap IV - Partição de um conjunto & MM1: Cap 5 - Partitions & \\
\hline & Cap V - Geometria & MM1: Cap 6 - Premiers éléments de géométrie & \\
\hline & Cap VI - Relações (1) & MM1: Cap 7 (1 $1^{\mathrm{a}}$ metade $)$ - Relations & \\
\hline & Cap VII - Relações (2) & MM1: Cap 7 (2 metade) - Relations & \\
\hline & Cap VIII - Relações (3) (Composição) & MM1: Cap 9 - Composition de relations & \\
\hline & Cap IX - Relações (4) (Ordens) & MM1: Cap 11 - Ordres & \\
\hline & Cap X - Relações (5) (Funções) & MM1: Cap 12 - Fonctions & \\
\hline & Cap XI - O grupo das permutações & MM1: Cap 13 - Permutations & \\
\hline & Cap XII - Transformações do plano & MM1: Cap 14 - Transformations du plan & \\
\hline & Cap XIII - Projeções paralelas e ordem & MM1: Cap 15 - Projections parallèles et ordre & \\
\hline & Cap IV - Cardinais & MM1: Cap 16 - Cardinaux & \\
\hline \multirow{9}{*}{ 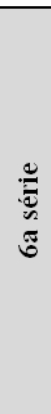 } & Cap I - Adição de Cardinais & MM1: Cap 17 - Addition & \multirow{7}{*}{ MM1 } \\
\hline & Cap II - Multiplicação de Cardinais & MM1: Cap 18 (parte) - Multiplication & \\
\hline & Cap III - Divisibilidade & MM1: Cap 18 (parte) - Multiplication & \\
\hline & Cap IV - O sistema binário de numeração & MM1: Cap 19 - Le système de numération binaire & \\
\hline & Cap V - Os inteiros Racionais & MM1: Cap 20 - Les entiers rationnels & \\
\hline & Cap VI - Equipolência - Translação - Vetor & $\begin{array}{r}\text { MM1: Cap } 21 \text { - Equipolência } \\
\text { Cap } 22 \text { - Translations }\end{array}$ & \\
\hline & Cap VII - Simetria Central & MM1: Cap 23 - Symétries centrales & \\
\hline & Cap VIII - Simetria Paralela & MM3: Cap 2 - Symétries parallèles & MM3 \\
\hline & Cap IX - Grupos & MM1: Cap 24 - Groupes & MM1 \\
\hline
\end{tabular}




\begin{tabular}{|c|c|c|c|c|}
\hline & & Apostilas de Dom Ireneu & Manuais de Papy & \\
\hline \multirow{9}{*}{ 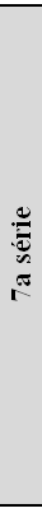 } & \multicolumn{2}{|c|}{ Cap I - Grupo e Ordem } & $\begin{array}{l}\text { MM2: Cap } 1 \text { - Le Groupe } \Pi \_(0,+), \\
\text { Cap } 2 \text { - Le Groupe D_(0,),+, } \leq, \\
\text { Cap } 3 \text { - Graduations de la droite, } \\
\text { Cap } 4 \text { - Axiome d'Archimède, } \\
\text { Cap } 5 \text { - Sous-graduations de la droite }\end{array}$ & \multirow{8}{*}{ MM2 } \\
\hline & \multicolumn{2}{|c|}{ Cap II - Os números Reais } & MM2: Cap 6 - Nombres réels & \\
\hline & \multicolumn{2}{|r|}{ Cap III - O grupo ordenado dos Reais R,+ } & MM2: Cap 7 - Le Groupe $R,+, \leq$ & \\
\hline & \multicolumn{2}{|r|}{ Cap IV - Teorema de Tales } & MM2: Cap 8 - Théorème de Thalès & \\
\hline & \multicolumn{2}{|c|}{ Cap V - Homotetia } & MM2: Cap 9 - Homothéties & \\
\hline & \multicolumn{2}{|c|}{ Cap VI - A multiplicação dos Reais } & MM2: Cap 10 - La multiplication des nombres réels & \\
\hline & \multicolumn{2}{|c|}{ Cap VII - Multiplicação escalar } & MM2: Cap 11 - La multiplication scalaire & \\
\hline & \multicolumn{2}{|c|}{ Cap VIII - O campo ordenado dos Reais } & MM2: Cap 12 - Le champ ordonné des nombres réels & \\
\hline & \multicolumn{2}{|c|}{ Cap IX - O vetorial R,D_ $(0)+}$, & \begin{tabular}{|c|} 
NÃO HÁ CORRESPONDENCIA EXATA COM OS \\
MANUAIS DE PAPY \\
\end{tabular} & \\
\hline \multirow{18}{*}{ 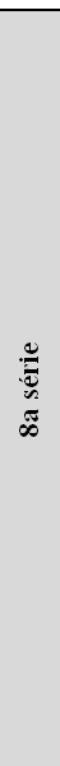 } & \multicolumn{2}{|c|}{ Cap I - Cálculo em R, +, .., $\leq$} & $\begin{array}{l}\text { MM2: Cap } 13 \text { - Dans le champ ordnné des nombres } \\
\text { réels }\end{array}$ & \multirow{2}{*}{ MM2 } \\
\hline & \multicolumn{2}{|c|}{ Cap II - Reais racionais e irracionais } & $\begin{array}{l}\text { MM2: Cap } 14 \text { - Nombres rationnels et nombres } \\
\text { irrationnels }\end{array}$ & \\
\hline & \multicolumn{2}{|c|}{ Raiz Quadrada } & MM3: Cap 16 - Racine carré & $\overline{\text { MM3 }}$ \\
\hline & \multicolumn{2}{|r|}{ 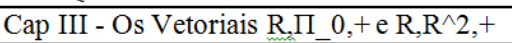 } & MM2: Cap 15-Les vectoriels & \multirow{3}{*}{ MM2 } \\
\hline & \multicolumn{2}{|c|}{ Cap IV - Equações das retas no plano } & MM2: Cap 16 - Equations des droites du plan & \\
\hline & Cap & V - Semi planos e inequações & MM2: Cap 17 - Demi-plans et inéquations & \\
\hline & \multicolumn{2}{|c|}{ Cap VI - Sistemas de equações lineares } & $\begin{array}{l}\text { NÃO HÁ NENHUMA CORRESPONDÊNCIA } \\
\text { COM OS PAPYS }\end{array}$ & \\
\hline & \multirow{11}{*}{ 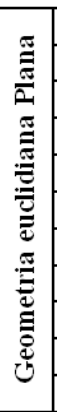 } & Cap I - Simetrias centrais & MM3: Cap 1 - Symétries centrales & \multirow{11}{*}{ MM3 } \\
\hline & & Cap II - Simetrias Paralelas & MM3: Cap 2 - Symétries parallèles & \\
\hline & & Cap III - Simetrias ortogonais & MM3: Cap 3 - Symétries orthogonales & \\
\hline & & Cap IV - Isometrias & MM3: Cap 4 - Isométries & \\
\hline & & Cap V - Deslocamentos & MM3: Cap 5-Déplacements & \\
\hline & & Cap VI - Rotações & MM3: Cap 6 - Rotations & \\
\hline & & Cap VII - Grupo dos deslocamentos & MM3: Cap 7 - Groupe des déplacements & \\
\hline & & Cap VIII - Reviramentos & MM3: Cap 8 - Retournements & \\
\hline & & Cap IX - Distância & MM3: Cap 9 - Distance & \\
\hline & & Cap X - Círculos & MM3: Cap 10 - Cercles & \\
\hline & & Cap XI - Produto escalar & MM3: Cap 11 - Produit scalaire & \\
\hline
\end{tabular}

\subsection{Dom Ireneu e sua escolha pelo Método Papy no Colégio de São Bento - justificativas próprias e objeções alheias}

Um amigo de Dom Ireneu e professor de matemática do Colégio de São Bento na década de 1970, interrogado sobre as razões pelas quais este se recusava a seguir os livros didáticos propostos pelos que difundiam o Movimento da Matemática Moderna, respondeu: 'Porque repugna, repugnava a um cara como Dom Ireneu, como a mim e a outros, fazer coisas mal feitas.” (José Paulo Carneiro - depoimento oral)

Dom Ireneu era um educador completamente inconformado com o ensino de matemática de sua época. Segundo José Paulo Carneiro, professor de matemática do curso científico no CSB no início da década de 1970, Dom Ireneu não se conformava com a falta de coerência entre os diversos assuntos matemáticos ensinados no colégio, e como os alunos eram introduzidos às ciências matemáticas, por meio dos livros didáticos disponíveis:

Quando se chegava no $3^{\circ}$ [ano científico], parecia até outra matemática. Falava de ponto, reta, postulado. E na realidade isso era furado [...] fazer uma parte axiomática pra geometria euclidiana é a coisa mais complicada de se fazer. Todo mundo sabe que Euclides e todas as ideias maravilhosas que ele teve estavam completamente furadas e quando Hilbert, o grande Hilbert, resolve consertar, ele faz uma axiomática que ninguém na vida 
prática pôde usar, e muito menos no ensino, porque no ensino, isso ia ficar um porre. Bom... Dom Ireneu não se conformava com isso e fazia outras coisas; muito antes, antes de Papy [...], ele sempre se expôs ao diferente, sempre fazia uma coisa diferente. (José Paulo Carneiro depoimento verbal)

Como coordenador de Matemática e coordenador do Ensino Ginasial no CSB, Dom Ireneu sempre mostrava novos livros ao professor Carneiro, que o acompanhava em sua busca por algo ideal para suas aulas de matemática. Foi assim que, em 1968, Dom Ireneu, um homem de cultura predominantemente francesa, adquiriu, não se sabe como, a coleção Mathématique Moderne de Papy e a apresentou ao professor Carneiro, junto com seu entusiasmo, já lhe confiando sua vontade de adotá-la em suas aulas:

Dom Ireneu sempre me mostrava livros - e tem outros [de] que eu não me lembro o nome... Até o dia em que exatamente ele me trouxe o Papy. - Vou te mostrar uma coisa, ele disse. Aí ele me mostrou [o Papy] e eu fiquei encantado! Eu fiquei encantadíssimo com o Papy. [...] A essência do Papy era exatamente essa mistura constante, essa mescla constante entre geometria e o resto da matemática. Ele acabou com esse negócio de separar a geometria. Desde o início então ele vai fazendo geometria, e vai fazendo uma geometria axiomática correta. Obviamente Dom Ireneu ficou encantado com isso e chegou pra mim - lembro disso lá na sala dos professores do São Bento - e me disse assim: "Se eu agora formar as turmas por aqui - porque eu finalmente encontrei um sistema coerente você aguenta eles lá no fim [nos três anos de científico]?" (José Paulo Carneiro - depoimento verbal)

Com a resposta afirmativa do professor Carneiro, Dom Ireneu decide então adotar os conteúdos e a metodologia expostos no Mathématique Moderne de Papy para o ensino primário do CSB, apoiado pelos professores do científico, que o seguiriam, e pelo reitor do CSB, Dom Lourenço de Almeida Prado:

Dom Lourenço, reitor do colégio, deu muita força a tudo isso e sempre apoiou Dom Ireneu, apesar de não ser da área de matemática - ele era médico. Dom Ireneu tinha total liberdade, total liberdade. Ele coordenava todo o ensino fundamental, o ensino de matemática, e dava aulas também. [...] Aquele espaço [de matemática] era dele. (José Paulo Carneiro - depoimento verbal)

Assim que o colégio introduziu o Método Papy em suas aulas de matemática do ginásio, Dom Ireneu escreveu uma circular aos pais e responsáveis dos alunos do $1^{\circ}$ ano do ginásio prevenindo-lhes desta recente mudança no ensino de matemática. Desta carta apreendemos as razões da escolha de Dom Ireneu - a busca por uma maior coerência.

Como a totalidade de manuais brasileiros disponíveis começou a introduzir os novos métodos e conceitos, sem porém alterar substancialmente a ordem das matérias e pontos tradicionalmente abordados, à medida que íamos expondo os conceitos fundamentais de Matemática pelos novos métodos, a própria necessidade de coerência nos foi distanciando desses manuais, obrigando-nos a fornecer aos alunos textos mimeografados das lições de exercícios. Na verdade, não era nossa 
intenção inicial enveredar por esses caminhos, quando mais não fosse pelo maior trabalho que daí nos adviria. (Penna, [1967 - 1970])

É possível que uma das mais fortes objeções feitas ao colégio quanto à adoção do novo método tenha sido em relação a não utilização dos manuais brasileiros de Matemática Moderna. Dom Ireneu dizia explicitamente que, a julgar pelos compêndios que conhecia e nesta lista inclui-se "o que foi publicado pelo professor Castrucci, de competência reconhecida" (PENNA, [1967 - 1970]) - a Matemática Moderna não vinha sendo bem ensinada no Brasil. Segundo ele o defeito essencial parecia estar no programa:

A diferença mais chocante no confronto com os programas correntes reside em que o programa de Lima $^{13}$ [que é o seguido nos manuais de Papy] conduz a uma exploração mais profunda das noções de conjunto, relação [...], transformações do plano...ao passo que o programa convencional tem uma pressa excessiva em abordar os "números" e as "operações", falhando desde o início no projeto de um pensamento matemático verdadeiramente novo (PENNA, 1968).

O então coordenador de matemática do CSB confia no método que escolheu e acredita, contrariamente a alguns pais e educadores, que a iniciação por meio da matemática moderna, ao modo feito por Papy, garante bases muito mais sólidas para os estudos superiores, em todos os ramos do conhecimento. Em uma entrevista concedida a um jornal do CSB, Dom Ireneu expõe seu pensamento:

[...] a MM moderna exerce um apelo mais universal sobre as inteligências. Dá a impressão de "um jogo mais limpo", onde tudo é posto às claras e nada se escamoteia. Tem recursos geniais para matematizar as situações concretas [...], fornecendo esquemas lógicos e hábitos de pensamento que se estendem a todos os ramos do saber. (Dom Ireneu apud FERNANDES, 1968, p.3)

De fato, após o estudo de um novo modelo matemático, Dom Ireneu tentava fazer uma tradução concreta do mesmo com seus alunos. Assim, foram construídos circuitos elétricos e calculadoras. $\mathrm{O}$ testemunho de um ex-aluno revela de forma muito explícita a "matematização" de um conteúdo de álgebra e de lógica:

Outra curiosidade era o computador booleano, que eu também reproduzi em casa... Eram quatro chaves de duas posições, cada uma com 12 pólos, quatro lâmpadas e uma bateria. Os polos das chaves eram trazidos à superfície do computador, em "jacks". Com cabos contendo "plugs", podíamos interligar os polos das chaves, da bateria e das lâmpadas. Pronto o computador, vinha a programação: montávamos a tabela verdade da função desejada, "codificávamos" com os cabos e, pronto: as lâmpadas acendiam de acordo com a tabela verdade. Um dos problemas que ele gostava era o de atravessar um homem, uma onça, um cabrito e uma cenoura de um lado para outro do rio; quando uma situação indesejada ocorria (a onça foi deixada sozinha com o cabrito), uma lâmpada acendia!

E ele me deixou um desafio, que era fazer um somador binário com chaves de 18 pólos. Ele conseguiu fazer e não deixei ele me contar a solução, pois eu também queria resolver... Durante alguns anos, tentei 
resolver, sem sucesso, e eu acabei esquecendo. O tempo passou, ele morreu e o desafio ficou... (Sérgio Lúcio Miranda - depoimento verbal)

Outro aspecto sobre o qual Dom Ireneu insistia muito era a questão da ordem lógica dos conteúdos. Foi esta uma de suas principais razões para abandonar os manuais tradicionais:

Como a totalidade de manuais brasileiros disponíveis começou a introduzir os novos métodos e conceitos, sem porém alterar substancialmente a ordem das matérias e pontos tradicionalmente abordados, à medida que íamos expondo os conceitos fundamentais de Matemática pelos novos métodos, a própria necessidade de coerência nos foi distanciando desses manuais, obrigando-nos a fornecer aos alunos textos mimeografados das lições de exercícios (PENNA, [1967 - 1970]).

Na obra de Papy, Dom Ireneu sentia coerência:

Ele [Papy] procura construir estruturas cada vez mais ricas, sistemas matemáticos que tenham uma quantidade enorme de interpretações; consistem em modelos matemáticos que vão ter traduções concretas e, portanto, representarão uma economia de pensamento. As estruturas vão transformar uma série de problemas diferentes num mesmo problema (Dom Ireneu apud Dom Ireneu apud COM QUANTOS MÉTODOS..., 1974).

Neste outro trecho da mesma carta dirigida aos pais e responsáveis, Dom Ireneu insiste novamente na questão da ordem lógica.

Os [...] alunos, em ordem um pouco diferente da usual (porém muito mais eficiente e racional) bem cedo verão todas as partes da Matemática tradicionalmente ensinadas e que tenham um valor perene e fundamental. Verão porém esses temas sob a luz superior e mais perfeita ordem lógica, de modo a dominá-los melhor e enquadrá-los em perspectivas mais amplas. Além disso, bem cedo terão contato com as partes mais vivas da Matemática, usualmente só estudadas mais tarde, com real prejuízo para os cursos de nível superior (PENNA, [1967 - 1970]).

Esta foi a resposta dada por Dom Ireneu à objeção - feita por parte de pais e educadores - de que seguindo um programa diferente, os alunos deixariam de aprender um certo número de assuntos que tradicionalmente fazem parte do programa de matemática do curso secundário e são eventualmente exigíveis em vestibulares e outros concursos externos. Para Dom Ireneu, "a preparação em Matemática Moderna dá uma visão mais ampla e mais correta" sem deixar "de habilitar o estudante a resolver os problemas tradicionais" (PENNA, 1968). Infere-se daí que as inquietudes dos pais e de alguns educadores a respeito de como se sairiam nos exames de vestibular os alunos oriundos de um sistema muito diferente ao proposto pelos programas usuais não inquietava tanto Dom Ireneu. Ele parecia ter certeza do sucesso de seus alunos nos vestibulares, pois acreditava que a formação da inteligência que estes receberiam ia muito além do exigido pelos exames nacionais.

Neste trecho, retirado de um artigo escrito no jornal $O$ Globo, Dom Ireneu solicita a confiança dos pais quanto ao trabalho que ele desenvolve no colégio: "Os pais devem 
confiar que nós estamos aplicando um método qualitativamente superior", afirma. (PENNA apud COM QUANTOS MÉTODOS ..., 1974).

Dom Ireneu dá mostras de ser um educador que via muito à frente. $\mathrm{O}$ sucesso dos alunos do CSB nestes exames pode ser confirmado em diversas fontes. Soares (2001) comenta este fenômeno, além de apontar depoimentos que testemunham que "um aluno do colégio é facilmente distinguido entre os demais por apresentar raciocínio rápido e melhor desempenho na resolução de problemas" (SOARES, 2001, p. 98). O ex-aluno Francisco Nóbrega, aluno das primeiras turmas de Dom Ireneu com o Método Papy, e que mais tarde, ainda como aluno de graduação, foi professor do curso científico no CSB, relembra:

Até hoje me divirto com a aflição dos pais querendo saber se aquele "método maluco" não iria causar problema para os seus filhos na hora do vestibular, sete anos depois!! Bom, não só não houve problema nenhum como diz a lenda que alguns caras daquela turma [...] fizeram uma quantidade escandalosa de pontos no vestibular, especialmente em Matemática (Francisco Nóbrega - depoimento verbal).

Ao comentar que "bem cedo [os alunos] terão contato com as partes mais vivas da Matemática, usualmente só estudadas mais tarde, com real prejuízo para os cursos de nível superior" (PENNA, [1967 - 1970]), acreditamos que Dom Ireneu se referia a conteúdos tanto de álgebra - grupos, anéis - quanto ao que hoje denominamos análise - a estrutura dos números reais, a enumerabilidade de conjuntos e questões sobre o infinito. Ainda na mesma circular aos pais, ele comenta que os alunos "abordarão as questões do 'infinito' matemático com um perfeito rigor lógico que os preparará corretamente para o cálculo diferencial e integral" (PENNA, [1967 - 1970]). E de fato todos estes tópicos constam nos registros dos cadernos do ginásio, tanto nas apostilas de conteúdo quanto nos manuais de Papy.

A abordagem vetorial, muito enfatizada na proposta de Papy, também é uma característica apreciada pelo monge. Ele percebe o cálculo vetorial como o laço que une a geometria à álgebra. Assim, os alunos teriam, com sua proposta, "o manejo inicial do mais poderoso instrumento de cálculo e teorização que é o cálculo vetorial e começarão a se familiarizar com a Geometria Analítica" (PENNA, [1967 - 1970]) muito antes do que costuma acontecer.

A partir deste entendimento, em relação ao tipo de ensino de matemática que seus alunos deveriam ter, percebe-se a elevada formação científica desejada pelo corpo docente de matemática e pelo reitor do CSB. Mas esta característica não é exclusiva da época analisada. O colégio sempre manteve esta linha de conduta - o que acontece até hoje tendo o método Papy vigorado no colégio até 2005, três anos antes do falecimento de Dom Ireneu e apesar de ele ter deixado para trás seu posto de professor e coordenador de matemática do colégio.

A adoção do método Papy era, para Dom Ireneu, a escolha de um método inteligente, que contribuía, a seu modo, com a formação da inteligência do indivíduo. Em diversas entrevistas ele sublinha a característica do método adotado e de que maneira se dá a colaboração da Matemática Moderna para o aperfeiçoamento do raciocínio matemático. Em 1969, em entrevista ao jornal $O$ Globo, ele expõe sua opinião sobre a Matemática Moderna:

[...] é uma matéria de formação real e libertação dos espíritos, fazendo com que o aluno raciocine por ele mesmo em busca da verdade e não seja apenas um tecnocrata. (DOM IRENEU apud FREI IRENEU, 1969). 
E novamente ao mesmo jornal, Dom Ireneu comenta, cinco anos depois, que

[...] a característica mais significativa do método inteligente do ensino da matéria é estar sempre ancorado no senso comum, no bom senso e quando aparece um formalismo ele não destrói o bom senso. [Durante a aula], toda a hora a gente quebra o formalismo, fazendo a criança explicar aquilo num modelo intuitivo (PENNA apud COM QUANTOS MÉTODOS, 1974).

Nas entrelinhas destes testemunhos, ele deixa entrever sua concepção tanto de educação matemática quanto de ensino e educação geral do homem: ensinar o aluno a pensar, organizar o raciocínio, convidar o aluno a conhecer, a utilizar e desenvolver sua inteligência e alcançar a verdade.

As atitudes e pensamentos de Dom Ireneu caminham em acordo com as concepções de educação de Dom Lourenço de Almeida Prado, o já citado reitor do Colégio de São Bento por 46 anos. Em um de seus vários livros sobre o tema, Dom Lourenço expõe sua visão filosófica sobre o que é educação:

No cerne do processo educativo está a verdade, [...] o conhecimento da verdade e sua conquista. $\mathrm{O}$ homem é um animal curioso, um animal que tem sede de saber e se alegra com a descoberta da verdade. A inteligência precisa da verdade, como de seu alimento. É iluminado pela verdade, aos poucos conquistada, que o ser humano vai se equipando com a faculdade de discernir, avaliar e escolher, de ponderar e decidir (PRADO, 1991, p.27 - grifo do autor).

É neste contexto filosófico sobre o que é educação que se deve entender as opiniões de Dom Ireneu a respeito dos conteúdos e metodologias apresentadas por Papy para uma Matemática Moderna.

Ainda na carta dirigida aos pais e responsáveis, Dom Ireneu escreve algumas palavras com o objetivo de tranqüilizar os pais a respeito de um "inconveniente inegável", conseqüência de sua decisão de adotar o Método Papy: o problema da recuperação e transferência de alunos. Adotando uma linha de conduta completamente diferente da usual, a recuperação de um aluno tornava-se um problema, pois não se encontrava facilmente um professor paralelo que tivesse o conhecimento necessário para auxiliá-lo do processo de recuperação. Os clássicos professores particulares não estavam formados naquela matemática proposta por Papy e ensinada no CSB. Muito menos os pais conseguiam acompanhar o que seus filhos aprendiam para eventualmente ajudá-los.

Segundo testemunho de Sandra Carelli, ex-professora do CSB na década de 1970, a matemática ensinada no colégio era uma matemática muito mais difícil, e não bastava ser professor da disciplina para ensinar a uma criança de 12 a 15 anos o que o colégio propunha: álgebra de Boole, enumerabilidade dos racionais, espaços vetoriais, álgebra, estrutura de grupos, etc. Era preciso ter sido formado neste sistema, como Sandra e algumas outras professoras do CSB o foram quando alunas de Dom Ireneu no curso de Licenciatura em Matemática da Universidade Santa Úrsula, na cidade do Rio de Janeiro.

A dificuldade era achar um professor particular que tivesse condições - entenda-se conhecimento de conteúdo - de ajudar um aluno do CSB que ficasse em recuperação.

Dom Ireneu enxergava esta dificuldade como adjacente a uma solução concreta. Toda solução carrega em si um inconveniente que deve ser aceito em vistas de um bem maior. "Não se faz omeletes sem quebrar ovos", comentava Dom Ireneu. Pedia aos pais 
que "não enxergassem o problema com lentes de aumento" e inclusive os convidava a não recorrerem a professores particulares. Não achá-los parecia até ser uma vantagem:

[...] vistos sob certo ângulo, alguns [...] inconvenientes passam a ser verdadeiras vantagens: o auxílio direto dos pais nos estudos das crianças é raramente desejável (prolonga ou agrava a maturidade); a instituição do "professor particular" é quase sempre um mero paliativo para adiar os fracassos, ou uma muleta para quem tem pernas. (PENNA, [1967 1970]).

O que fazer então com os alunos em recuperação? Que chances lhes eram dadas de tentar recuperar? Ao fim de uma etapa ou de outra, Dom Ireneu pedia a alguma de suas exalunas que dessem aulas particulares a um ou outro aluno que não tivesse alcançado a nota mínima. Maria Isabel Carvalho é uma destas ex-alunas. Em depoimento verbal, conta que deu poucas aulas, somente para alunos de famílias conhecidas, mas que em geral não havia muitos alunos em recuperação. E comentou como as coisas aconteciam: "Dom Ireneu falava com a gente, perguntando se podia ajudar fulano ou sicrano, que a gente conhecia, para a recuperação de matemática. Era bem informal" (Maria Isabel Carvalho, depoimento verbal).

Outros testemunhos indicam que, dentre os alunos que ficavam em recuperação em matemática, poucos eram os que efetivamente se recuperavam. Alguns que não passavam eram convidados a mudar de instituição, outros repetiam o ano. Cada caso era analisado separadamente.

Mas a situação de um aluno que saía do Colégio de São Bento e ia para outro colégio também não era nada confortável. Tendo seguido um currículo nada usual, acompanhar as aulas de matemática em outro colégio era estranho e difícil para o aluno oriundo do CSB. Quanto a este inconveniente, Dom Ireneu (PENNA, [1967 - 1970]) se limita a dizer que isso não é um problema exclusivo do CSB. De certa forma ele não se responsabiliza por este inconveniente, e aponta uma brecha na Lei de Diretrizes e Bases (LDB) da qual ele se serviu para adotar o Método Papy. "A transferência para outro colégio, depois da Lei de Diretrizes e Bases (que libertou os currículos e programas) em qualquer caso criaria problemas de adaptação..." (PENNA, [1967 - 1970]). De fato, a LDB de 1961 não determina os currículos e programas das disciplinas para as escolas. Tampouco o fazem as Leis de Diretrizes e Bases subsequentes nem o extinto Conselho Federal de Educação (CFE).

\section{Considerações finais}

Desta primeira análise sobre alguns aspectos de como se deram os anos iniciais da introdução do método Papy no Colégio de São Bento percebe-se a firmeza e convicção de seu introdutor, Dom Ireneu, o que de certa forma contribuiu para o sucesso desta iniciativa. Como dito acima, era Dom Ireneu um personagem de temperamento forte. É bem possível que o CSB não tivesse embarcado em tal empreitada se não fosse pela ação de um monge com tal determinação, influência, cultura e preparo intelectual. Ele tinha certeza de que o método, um conjunto de conteúdos e metodologia, era superior ao que se tinha na época, não só em termos científicos, mas em termos de formação geral da inteligência.

Para finalizar, transcrevemos um apelo de Dom Ireneu de tomada de consciência por parte dos pais sobre o que de fato consistia o Método Papy. Segue-se a este apelo uma reflexão a respeito da novidade que era o método e explica, ainda que brevemente, a maneira como pretende agir em relação ao aprendizado dos alunos: 
Tanto os pais como os professores têm dificuldade de se reciclar, o que exige um esforço enorme. Há dois extremos de pais: uns que não conseguindo entender o que os filhos estão aprendendo estimulam a criança e outros que tão logo a criança esbarre numa dificuldade pode fazer exclamações do tipo 'eu não aprendi isso nem na Escola de Engenharia, o professor deve estar louco'.

Os pais devem confiar que nós estamos aplicando um método qualitativamente superior, que dá chances à criança de ser tão inteligente o quanto pode, desde que a gente não atormente o menino, aproveite qualquer vislumbre que surja e também a gente saiba que de alguns não se pode exigir o mesmo que de outros; então a gente se contenta com o menos de alguns e o mais de outros (PENNA apud COM QUANTOS MÉTODOS ..., 1974 - grifos no original).

\section{Referências}

BRITTO, L. P. Scipione di Pierro Neto e sua proposta para o ensino da geometria na Coleção Curso Colegial Moderno. Dissertação de Mestrado Profissionalizante, Centro das Ciências Exatas e Tecnologias, Pontifícia Universidade Católica de São Paulo, 2008.

CHERVEL, A. História das disciplinas escolares: reflexões sobre um campo de pesquisa. Teoria e Educação, Porto Alegre, n. 2, 1990, p. 177-229.

COLAÇO, W. S. Movimento da matemática moderna aos tempos atuais: uma análise de livros didáticos sobre explicitação e exploração das propriedades de operações. Dissertação de Mestrado Profissionalizante, Departamento de Ensino de Ciências, Universidade Estadual da Paraíba, 2010.

DOBROWOLSKI, E. N. Implantação da matemática moderna na década de 1960 e 1970 no município de Pato Branco - PR. Dissertação de Mestrado, Departamento de Educação, Pontifícia Universidade Católica do Paraná, 2011.

DUARTE, A. R. S. Matemática e educação matemática: a dinâmica de suas relações ao tempo do movimento da matemática moderna no Brasil. Tese de Doutorado, Departamento de Educação Matemática, Pontifícia Universidade Católica de São Paulo, 2007.

FIETTA, L. C. Dienes e os guias curriculares de Matemática de São Paulo na década de 1970: um estudo sobre as influências. Dissertação de Mestrado, Departamento de Educação Matemática, Universidade Bandeirante de São Paulo, 2010.

FRANÇA, D. M. A. A produção oficial do Movimento da Matemática Moderna para o ensino primário do estado de São Paulo (1960-1980). Dissertação de Mestrado, Departamento de Educação Matemática, Pontifícia Universidade Católica de São Paulo, 2007.

FRAZÃO, A.; NOUGUÉ, C. Colégio de São Bento do Rio de Janeiro: 150 anos de história, 1858-2008. Rio de Janeiro, Ed. Letra Capital, 2008.

GVIRTZ, S. El discurso escolar a través de los cuadernos de clase. Argentina (19301970). Buenos Aires: Eudeba, 1999. 
MATOS, J.M.; VALENTE, W.R. (Orgs.) A Matemática Moderna nas escolas do Brasil e de Portugal: primeiros estudos. São Paulo: GHEMAT, 2007.

. (Eds.) A reforma da Matemática Moderna em contextos ibero-americanos. Lisboa: UIED, 2010.

MOSTEIRO DE SÃO BENTO. Pedras Vivas. Revista dos oblatos seculares do Mosteiro de São Bento do Rio de Janeiro. Ano XI. Novembro-Dezembro 2008. No. 47.

PAPY, G. Mathématique Moderne. Bruxelas: Didier,1968. 2V. 1967. 1V.

PRADO, L. A. Educação. Ajudar a pensar, sim. Conscientizar, não. Rio de Janeiro: Agir, 1991.

SANTANDER, C. V. B. O trabalho do professor Sylvio Nepomuceno, ajudando a reconstituir a história da educação matemática ao tempo de influência do Movimento da Matemática Moderna. Dissertação de Mestrado Profissionalizante, Centro das Ciências Exatas e Tecnologias, Pontifícia Universidade Católica de São Paulo, 2008.

SOARES, F.S. O movimento da Matemática moderna no Brasil: avanço ou retrocesso. Dissertação de Mestrado, Departamento de Matemática, Pontifícia Universidade Católica do Rio de Janeiro. Rio de Janeiro, 2001.

VILLELA, L.M.A. GRUEMA - Uma Contribuição para História da Educação Matemática no Brasil. Tese de Doutorado, Departamento de Educação Matemática, Universidade Bandeirante de São Paulo, 2009.

VIÑAO, A. Os cadernos escolares como fonte histórica: aspectos metodológicos e historiográficos. In MIGNOT, A. C. V. (Org). Cadernos à vista: escola, memória e cultura. Rio de Janeiro: EdUERJ, 2008. pp. 15-33.

\section{Fontes primárias}

COM QUANTOS MÉTODOS se faz uma didática à brasileira. O Globo, Rio de Janeiro, 10 nov. 1974. Educação, p. 26.

DOM IRENEU Pena confirma as suas denúncias. O Globo, Rio de Janeiro, 05 de setembro de 1968, Segundo Caderno, p. 3.

FERNANDES, C. A. P. [Org.] Dom Ireneu nos fala sobre a "Matemática Moderna". O Leão, Rio de Janeiro, abr-mai 1968. Gente importante. p. 3.

FREI IRENEU acha que os estudantes devem apreciar a Matemática. O Globo, Rio de Janeiro, 26 ago 1969. Educação, p. 13.

PENNA, I. Entrevista. Boletim da Associação de Pais e Mestres do Colégio de Aplicação, 3 de março de 1968.

[Circular]. Rio de Janeiro [para] Pais ou responsáveis por alunos da $1^{\text {a }}$ série ginasial do Colégio São Bento. 3f. Tem por fim prestar contas e dar alguns esclarecimentos sobre a introdução do novo método de ensino de Matemática no Colégio. [1967 - 1970]. 


\section{Notas}

\footnotetext{
${ }^{1}$ Professor Adjunto III da Faculdade de Educação da Universidade Federal Fluminense, Doutor em Educação e Mestre em Matemática pela Pontifícia Universidade Católica do Rio de Janeiro (PUC-Rio).

${ }^{2}$ Professora da rede particular de ensino de Niterói-RJ, Mestre em Ensino de Matemática pela Universidade Federal do Rio de Janeiro (UFRJ).

${ }^{3}$ Professor Visitante do Programa de Pós-Graduação em Educação Matemática do Instituto de Matemática (INMA) da UFMS.
}

${ }^{4}$ Pesquisa realizada em 25 de junho de 2013.

${ }^{5}$ Ver, por exemplo, http://www.unifesp.br/centros/ghemat/paginas/projetos.htm

${ }^{6}$ Organização Social da Política Brasileira

${ }^{7}$ Este acervo foi catalogado e inventariado durante um projeto de Iniciação Científica na Universidade Federal Fluminense desenvolvido em 2011. O resumo do relatório final do projeto está disponível em http://www.revistapibic.uff.br/images/PDF/Humanas\%202.pdf, p.42-43.

${ }^{8}$ Para a listagem dos tópicos abordados na $1^{\mathrm{a}}$ série ginasial utilizou-se o Apontamentos de Matemática 1, o primeiro volume de quatro apostilas escritas e utilizadas por Dom Ireneu em suas aulas, no ginásio. A listagem dos conteúdos das demais séries foi elaborada a partir dos cadernos do acervo. Quando conveniente, citam-se e comparam-se os cadernos e os Apontamentos de Matemática. As apostilas consultadas datam da década de 1980, com exceção do primeiro volume que data do final da década de 1970.

9 Teorema da Injeção: Se A e B são [conjuntos] finitos e equipotentes, então toda injeção: $A \rightarrow B$ é uma bijeção: $A \rightarrow B$. Em particular, toda injeção $A \rightarrow A$ é uma permutação de $\mathrm{A}$ (bijeção $A \rightarrow A$ ) (Apontamentos de Matemática I, 1976, p.122).

10 Teorema do Sanduiche: Se um conjunto é equipotente a uma de suas partes próprias, então ele é equipotente a todo conjunto intercalado: $C \supset Q \supset P$ e C e P têm o mesmo cardinal, então $\mathrm{C}$ e $\mathrm{Q}$ também têm o mesmo cardinal (Apontamentos de Matemática I, 1976, p.122).

${ }^{11}$ O tema graduação binária está vinculado ao estudo de graduação da reta, que vem a ser o estudo da representação gráfica da reta e dos números (binários ou decimais) na reta. $\mathrm{Na}$ reta graduada estarão representados os números [pontos] marcados a partir do 0 e do 1, que são os referenciais da reta graduada. Uma vez os referenciais estabelecidos, podem-se intercalar pontos intermediários entre dois pontos consecutivos, fazendo uma subgraduação. Assim, os pontos da graduação e das subgraduações sucessivas localizam os decimais (ou os binários) limitados. Por exemplo, os pontos da terceira subgraduação serão marcados com decimais (ou binários) de 3 algarismos depois da vírgula

${ }^{12}$ Por binários entendem-se os numerais representados em base binária.

${ }^{13} \mathrm{O} 2^{\circ}$ Congresso Interamericano de Educação Matemática teve lugar em Lima, de 5 a 12 de dezembro de 1966.

Recebido: novembro-13 Aprovado: outubro-14 